\title{
Prognosis and efficiency of adjuvant therapy in resected colon signet-ring cell carcinoma
}

\author{
Jingxu Sun", Xin Wang", Peng Gao, Yongxi Song, Xiaowan Chen, Yu Sun, Dehao Yu, Xinger Lv, \\ Zhenning Wang
}

Department of Surgical Oncology and General Surgery, The First Hospital of China Medical University, Shenyang 110001, China

Contributions: (I) Conception and design: Z Wang; (II) Administrative support: Y Song; (III) Provision of study materials or patients: X Wang, D Yu, X Lv; (IV) Collection and assembly of data: Y Sun, X Chen; (V) Data analysis and interpretation: J Sun, P Gao; (VI) Manuscript writing: All authors; (VII) Final approval of manuscript: All authors.

\#These authors contributed equally to this work.

Correspondence to: Zhenning Wang. Department of Surgical Oncology and General Surgery, The First Hospital of China Medical University, 155 North Nanjing Street, Heping District, Shenyang 110001, China. Email: josieon826@sina.cn.

Background: Colon signet-ring cell carcinoma (SRCC) is associated with poor survival compared with other histologic subtypes such as adenocarcinoma (AC) and mucinous adenocarcinoma (MC). This present study analyzed the prognosis factors of SRCC and assessed whether the adjuvant therapy could supply benefit for SRCC with different regimens.

Methods: Data on 82,606 colon cancer patients who received surgery in the period 1992-2005 was included in this population-based study. The survival benefit was evaluated using a Cox proportional hazards model and propensity score (PS)-matched techniques.

Results: SRCC was found in $779(0.9 \%)$ patients who were more frequently in stage III and IV colon cancer than other subtypes. The 5-year survival of SRCC patients were $30.1 \%$ (95\% CI, 26.7-33.5\%) which was significantly lower compared with 51.6\% (95\% CI, 51.3-52.0\%) for AC and 48.8\% (95\% CI, $47.8-49.8 \%)$ for MC. For patients in stage II, there was no significantly difference between chemo group and no-chemo group in all histologic subtypes. The results in stage III showed that 5-FU based adjuvant chemotherapy for AC and SRCC patients could improve overall survival (OS) which could be further enhanced by adding oxaliplatin. The similar benefit was found in stage IV patients. However, there was no significantly difference between different therapy regimens in stage IV SRCC patients.

Conclusions: Although the prognosis of patients with colon SRCC was pessimistic, the effective role of adjuvant therapy for OS was still observed in stage III SRCC patients who received surgery. Similarly, patients with stage IV SRCC could also gain benefit from systemic therapy.

Keywords: Colon cancer; Surveillance, Epidemiology, and End Results (SEER) program; signet-ring cell carcinoma (SRCC); adjuvant therapy; prognosis

Submitted Mar 16, 2018. Accepted for publication Jul 12, 2018.

doi: $10.21037 /$ tcr.2018.07.14

View this article at: http://dx.doi.org/10.21037/tcr.2018.07.14

\section{Introduction}

Colorectal cancer (CRC) is the third most commonly diagnosed malignancy and the second leading cause of cancer related death in the United States $(1,2)$. Three major histological subtypes of CRC have been defined by the World Health Organization including adenocarcinoma
(AC), mucinous adenocarcinoma (MC) and signet-ring cell adenocarcinoma (SRCC) (3). ACs are the most common subtype of CRC, with MCs accounting for approximately $10 \%$ of cases, and SRCCs accounting for only one percent of cases $(4,5)$. The SRCC subtype was first described in 1951 by Laufman and Saphir as an intracellular 
mucous accumulation and indenting of the nuclei to margin (6). SRCC is characteristically associated with younger patients, lower curative resection rates, localization to the right hemi colon, having an advanced tumor-nodemetastasis (TNM) stage and higher peritoneal metastasis (5,7-9). The mechanism of its malignant biological behavior may be due to its higher invasive potential, which may be influenced by higher expression of proteolytic enzymes and lower expression of adhesion molecules than other subtypes of CRC $(10,11)$. At present, investigations have indicated that SRCC has a poorer prognosis and is less responsive to treatment than other subtypes of CRC. The 5 -year survival rate of SRCC patients has been found to be less than $30 \%$ with a median survival time of 1 to 3 years (12-14). However, whether the prognostic impact is relevant for colon cancer patients is still poorly understood.

Treatments for colon cancer have improved in recent years, providing more effective treatment strategies. The use of adjuvant therapy remains a controversial option for the treatment of stage II colon cancer patients $(15,16)$. However, adjuvant chemotherapy with fluorouracil has been shown to improve the prognosis of stage III colon cancer patients following tumor resection (17). While oxaliplatin has become a standard component of treatments such as FOLFOX or CapeOx, there are still some studies which suggest that oxaliplatin may not be applicable for all patients receiving chemotherapy $(18,19)$. It is unclear whether distinguishing between CRC histological subtypes could aid in the selection of an appropriate chemotherapeutic strategy. The CRC histological subtypes are neither mentioned as factors for selection of colon cancer adjuvant chemotherapy in National Comprehensive Cancer Network (NCCN) or the European Society for Medical Oncology (ESMO). Moreover, there are few studies which focus on the influence of distinct histological subtypes on how CRC patients respond to treatment. Hugen et al. found that adjuvant chemotherapy could improve the survival of stage III colon SRCC patients with data from the Netherlands Cancer Registry (14). However, additional studies focusing on different stages and treatment strategies of colon SRCC are needed to inform the clinical practice.

In this population-based retrospective study, we analyze the clinicopathological characteristics of different histological subtypes of colon cancer. We then establish the prognostic impact of colon SRCC, assessing the relative benefits of distinct chemotherapeutic regimens on colon SRCC patients following resection.

\section{Methods}

\section{Data source}

The present study was a retrospective analysis using data acquired from the Surveillance, Epidemiology, and End Results (SEER)-Medicare linked database. This study was conducted in accordance with a SEER-Medicare data use agreement. A study protocol approval was also granted by the First Hospital of China Medical University Institutional Review Board.

SEER data contains information on patient demographics, tumor and disease characteristics, course of treatment, use of cancer-directed operative and medical therapy, survival, and cause of death for individuals diagnosed with cancer. It is a population-based cancer registry covering approximately $28 \%$ of the US population across several disparate geographic regions (20). Medicare is the primary health insurer for approximately $97 \%$ of the US population aged $\geq 65$ years (21). The unmentioned details of the database were described elsewhere (22).

\section{Patient selection}

All Medicare-registered patients diagnosed with incident malignant primary colon cancer (SEER cancer site codes: 18.0, 18.2-18.9) between 1992 and 2009 in a SEER area were considered for study inclusion. The study contained three histological types defined by WHO International Classification of Diseases for Oncology, $3 \mathrm{rd}$ edition (ICD-O-3), codes: AC [8010, 8020-8022, 8140-8141, 8144-8145, 8210-8211, 8220-8221, 8230-8231, 82608263], MC [8480] and SRCC [8490].

For stage II-III colon cancer, patients who underwent primary tumor resection with likely curative intent within 180 days of diagnosis. The no-chemo group was designated as patients with no claim of postoperative chemotherapy within 9 months after operation. The 5-FU group consisted of patients who only received 5-FU/capecitabine chemotherapy within 9 months of surgery. The FOLFOX group comprised patients with any record of oxaliplatin plus 5-FU/capecitabine within 9 months of surgery.

For stage IV colon cancer, patients were selected who received surgery within 180 days of diagnosis. The nochemo group was designated as no claim of perioperative chemotherapy from the day of diagnosis to 9 months after operation. The 5-FU group consisted of patients who only received 5-FU/capecitabine chemotherapy 
from the diagnosis day to 9 months after surgery. The FOLFOX/FOLFIRI group comprised patients with any record of oxaliplatin or irinotecan plus 5 -FU/capecitabine from the day of diagnosis to 9 months after surgery. The Bevacizumab group selected patients who received FOLFOX or FOLFIRI with bevacizumab from the diagnosis day to 9 months after operation.

Patients were eliminated from the study population if they: (I) were stage II-III patients who received any preoperative neoadjuvant treatment; (II) received postoperative radiotherapy; (III) had prior non-colon cancer; (IV) had incomplete histological subtype or pathological stage entries; (V) died within 30 days after tumor resection.

\section{Variables}

Subjects were categorized by age at diagnosis, year of diagnosis, gender, race, marital status, residence (rural or urban), median household income, level of education (percentage of people aged $>25$ years with $<12$ years of education). To control for the effects of comorbidities, analyses were adjusted by the Centers for Medicare and Medicaid Services Hierarchical Condition Category (HCC) based on Medicare outpatient and inpatient claims for miscellaneous comorbidities within the 12 months before colon cancer diagnosis. The HCC risk score summarizes the health care problems and forecasts the future health care cost of a population compared with the average Medicare beneficiary (23).

The postoperative pathological stage was designated via the seventh edition of the Union for International Cancer Control (UICC) TNM staging system (24). Other covariates included histological grade, histological subtype, intestinal obstruction, intestinal perforation, and the number of lymph nodes examined.

\section{Statistical analysis}

The $\chi^{2}$ test was used to compare demographics and tumor characteristics between the different groups. In the univariate survival analysis, overall survival (OS) was analyzed by the Kaplan-Meier method. Comparison of survival curves was carried out using the log-rank test. Because treatment choice estimates are likely confounded by factors related to treatment selection, a propensity score (PS)-matched analysis was performed to compare the effect of treatment on survival among patients of similar risk profiles as assessed by measured known confounders $(25,26)$.
PS matching is a statistical procedure for reducing this bias by assembling a sample in which confounding factors are balanced between treatment groups. Univariate logistic regression was used to find factors related to treatment selection $(\mathrm{P}<0.05)$. Multivariate logistic regression was used to estimate the PSs in each group. The PS-matched sample would then be constructed using "psmatch2" software package in STATA 12.0. A Cox proportional hazards model was also used in the adjusted analysis. The covariates included all variables that were identified to be significantly related to survival in the univariate analysis. All statistical analyses and graphics were performed using SAS 9.4 (SAS Institute, Cary, NC, USA), STATA 12.0 software (STATA, College Station, TX, USA), and PASW Statistics 18.0 software (SPSS, Inc., Somers, NY, USA). For all analyses, a $\mathrm{P}$ value $<0.05$ was considered statistically significant.

\section{Results}

\section{Patient characteristics}

A total of 82,606 patients were included in the present study, with most cases diagnosed as ACs ( $\mathrm{n}=71,656,86.7 \%)$. MCs were found in $12.3 \%$ patients and SRCCs accounted for just $0.9 \%$ of colon cancer patients who had received surgery (Table 1). In SRCC patients, the primary tumors were more frequently found in the right-side colon $(83.1 \%)$ than AC $(63.1 \%)$ or MC $(78.3 \%)$ patients $(\mathrm{P}<0.01)$. SRCC patients also presented more frequently with a poor and undifferentiated histologic grade than the AC or MC groups ( $82.7 \%$ vs. $21.4 \%, 21.5 \%, \mathrm{P}<0.01$, respectively). Regarding the pTNM stages, SRCC patients were more likely to be diagnosed as pT4 (25.8\%) compared with AC patients $(11.7 \%)$ or MC patients (15.3\%). SRCC patients were also more likely to be diagnosed as $\mathrm{pN} 3(42.1 \%$ vs. $13.8 \%, 17.1 \%, \mathrm{P}<0.01$, respectively). Furthermore, more stage III and IV patients were observed to have the SRCC subtype than AC or MC subtype (stage III $47.5 \%$ vs. $27.4 \%$, $30.4 \%, \mathrm{P}<0.01$; stage IV $24.9 \%$ vs. $14.1 \%, 15.5 \%, \mathrm{P}<0.01$, respectively). Compared with the AC (33.6\%) and MC (34.1\%) groups, patients in the SRCC group (42.5\%) were found to be more likely to suffer from intestinal obstruction after surgery $(\mathrm{P}<0.01)$.

\section{Subtype as a prognostic factor}

Patients in the SRCC group had a statistically significant poorer 5 -year survival than patients in the AC or MC groups 
Table 1 Demographic and clinicopathological features of patients with colon cancer diagnosed between 1992 and 2009

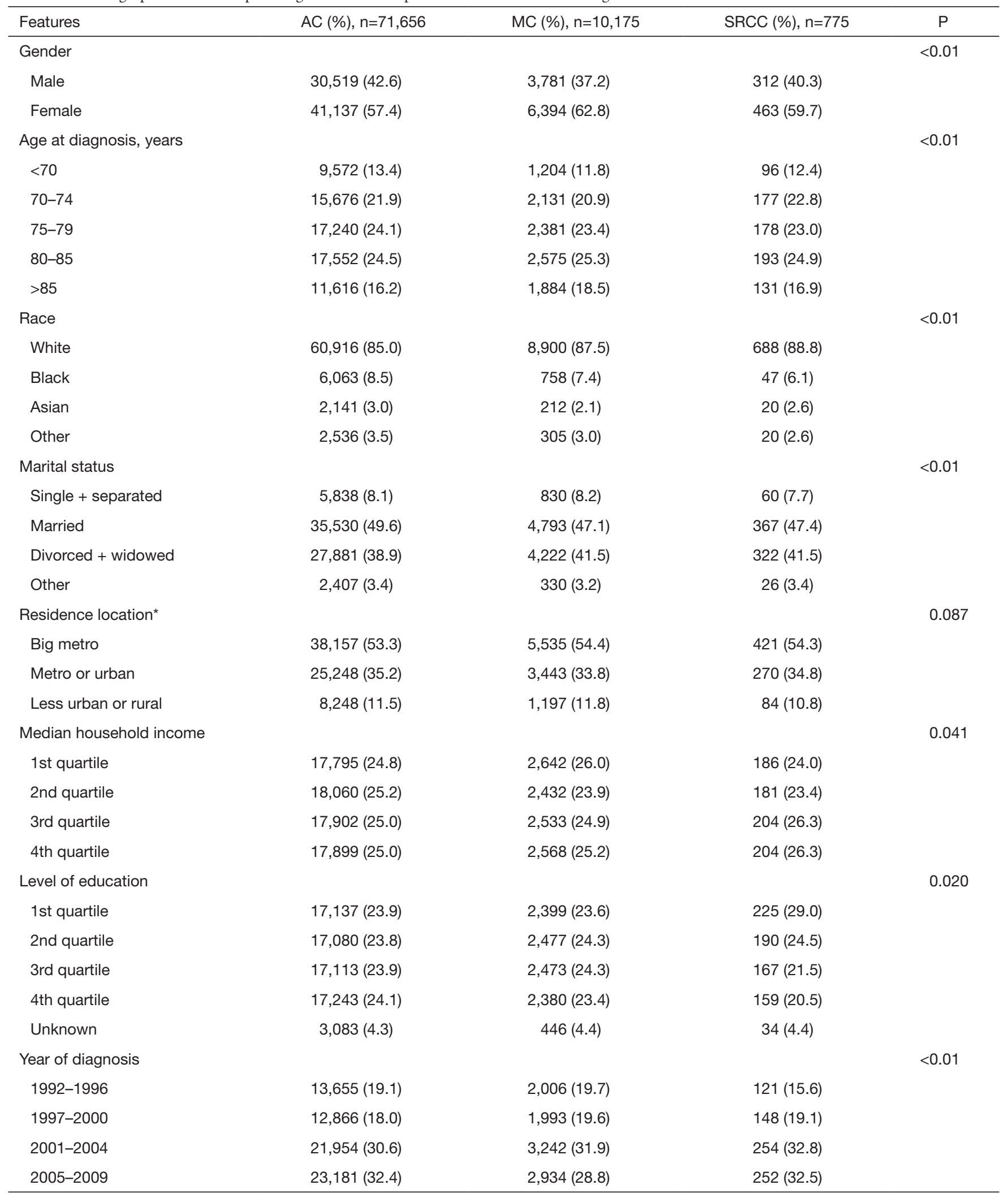

Table 1 (continued) 
Table 1 (continued)

\begin{tabular}{|c|c|c|c|c|}
\hline Features & $\mathrm{AC}(\%), \mathrm{n}=71,656$ & $\mathrm{MC}(\%), \mathrm{n}=10,175$ & $\operatorname{SRCC}(\%), \mathrm{n}=775$ & $P$ \\
\hline Left-sided colon & 26,447 (36.9) & $2,210(21.7)$ & $131(16.9)$ & \\
\hline Right-sided colon & $45,209(63.1)$ & 7,965 (78.3) & $644(83.1)$ & \\
\hline Histologic grade & & & & $<0.01$ \\
\hline Unknown & 2,364 (3.3) & $763(7.5)$ & $80(10.3)$ & \\
\hline pT category & & & & $<0.01$ \\
\hline pT1 & $8,333(11.6)$ & $406(4.0)$ & $18(2.3)$ & \\
\hline pT2 & 10,439 (14.6) & $1,257(12.4)$ & $34(4.4)$ & \\
\hline pT4b & $3,489(4.9)$ & $662(6.5)$ & $94(12.1)$ & \\
\hline Unknown & $6,254(8.7)$ & $1,006(9.9)$ & $110(14.2)$ & \\
\hline $\mathrm{pN}$ category & & & & $<0.01$ \\
\hline pNO & $45,254(63.2)$ & $5,999(59.0)$ & 258 (33.3) & \\
\hline pN1 & $8,141(11.4)$ & $1,171(11.5)$ & $71(9.2)$ & \\
\hline pN2 & $8,343(11.6)$ & $1,268(12.5)$ & $119(15.4)$ & \\
\hline $\mathrm{pN} 3 \mathrm{a}$ & $5,605(7.8)$ & $881(8.7)$ & $98(12.6)$ & \\
\hline $\mathrm{pN} 3 \mathrm{~b}$ & $4,313(6.0)$ & $856(8.4)$ & $229(29.5)$ & \\
\hline No & $47,585(66.4)$ & $6,703(65.9)$ & 446 (57.5) & \\
\hline Yes & $24,071(33.6)$ & $3,472(34.1)$ & 329 (42.5) & \\
\hline Intestinal perforation & & & & 0.047 \\
\hline No & $69,632(97.2)$ & $9,897(97.3)$ & 742 (95.7) & \\
\hline Yes & $2,024(2.8)$ & $278(2.7)$ & $33(4.3)$ & \\
\hline HCC risk score & & & & $<0.01$ \\
\hline 1st quartile & $17,994(25.1)$ & $2,751(27.0)$ & $191(24.6)$ & \\
\hline 2nd quartile & $17,542(24.5)$ & 2,323 (22.8) & $179(23.1)$ & \\
\hline 3rd quartile & $18,316(25.6)$ & $2,470(24.3)$ & $199(25.7)$ & \\
\hline 4th quartile & $17,804(24.8)$ & 2,631 (25.9) & 206 (26.6) & \\
\hline Number of examined lymph node & & & & $<0.01$ \\
\hline$<12$ & $36,147(50.4)$ & $5,491(54.0)$ & $453(58.5)$ & \\
\hline$\geq 12$ & $35,509(49.6)$ & $4,684(46.0)$ & $322(41.5)$ & \\
\hline
\end{tabular}

*, Variables have missing data. AC, adenocarcinoma; MC, mucinous adenocarcinoma; SRCC, signet-ring cell carcinoma. 
following surgery (Figure 1). The SRCC 5 -year survival rate was found to be $30.1 \%$ (95\% CI, 26.7-33.5\%), which is significantly lower than the 5 -year survival rates of $51.6 \%$ (95\% CI, 51.3-52.0\%) in AC and 48.8\% (95\% CI, 47.8-49.8\%) in MC (Table 2). The 5 -year survival rates for each TNM stage are also shown in Table 2. The results of survival analysis indicate that survival rates differ between CRC subtypes most prominently in stage III and IV colon cancer patients.

\section{Adjuvant chemotherapy for stage II SRCC colon cancer patients}

For stage II SRCC colon cancer, $17.8 \%$ of the patients received 5-FU based adjuvant chemotherapy compared

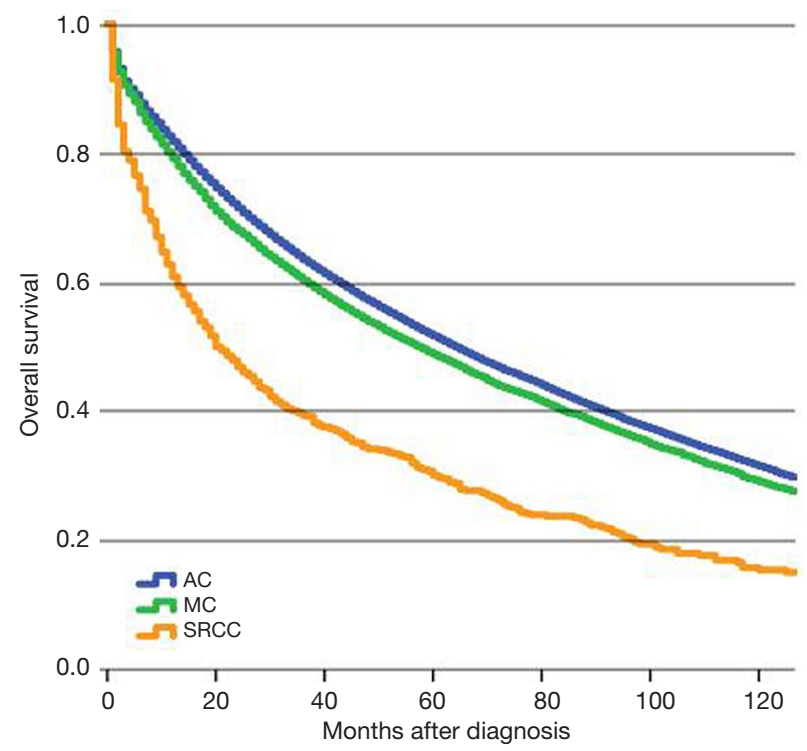

Figure $1 \mathrm{OS}$ in AC, MC and SRCC patients with colon cancer. OS, overall survival; AC, adenocarcinoma; MC, mucinous adenocarcinoma; SRCC, signet-ring cell carcinoma. with $17.2 \%$ in AC. There was a significant difference in survival for AC patients between no-chemo and 5-FU groups $(\mathrm{P}<0.01)$, but no significant difference between 5 -FU and FOLFOX groups $(\mathrm{P}=0.549)$ of AC patients (Figure $2 A)$. However, for patients with SRCC, 5-FU and FOLFOX did not show any benefit for OS compared with the no-chemo group ( $\mathrm{P}=0.067, \mathrm{P}=0.457$, respectively) (Figure $2 B$ ). We also verified the independent prognostic factors for OS by using a Cox proportional hazards model (Table 3).

PS-matched cohorts were then used to recalculate the above results. For AC group, the relevant confounding factors after PS-matched analysis of 5-FU group and nochemo group included gender, age, race, marital status, income, level of education, primary tumor site, $\mathrm{pT}$ category, intestinal obstruction, intestinal perforation, HCC risk score and number of examined lymph node. The relevant confounding factors after PS-matched analysis of 5-FU group and FOLFOX group included age, marital status, income, level of education, primary tumor site, $\mathrm{pT}$ category, intestinal obstruction, intestinal perforation and HCC risk score. For SRCC group, there were no relevant confounding factors after PS-matched analysis of 5-FU group and no-chemo group, while race, histologic grade and intestinal perforation were included in analysis of 5-FU group and FOLFOX group. The prognosis of patients with stage II AC who received 5-FU was better than the no-chemo group $(\mathrm{P}<0.01)$ but was not significantly different from the FOLFOX group $(\mathrm{P}=0.799)$ (Figure 2C,D). For patients with stage II SRCC, there was still no significant prognostic difference between the no-chemo group and the $5-\mathrm{FU}$ group $(\mathrm{P}=0.787)$ or the FOLFOX group $(\mathrm{P}=0.829)$ (Figure $2 E, F)$.

\section{Adjuvant chemotherapy for stage III SRCC colon cancer patients}

Following surgery, $53.1 \%$ of SRCC colon cancer patients

Table 2 Five-year relative survival with 95\% CI for patients with colon cancer in the US according to stage of disease and histology [1992-2009]

\begin{tabular}{lccc}
\hline Stage & AC $(95 \% \mathrm{Cl})$ & $\mathrm{MC}(95 \% \mathrm{Cl})$ & $\mathrm{SRCC}(95 \% \mathrm{Cl})$ \\
\hline I & $72.3(71.6-73.0)$ & $69.4(66.8-71.9)$ & $56.2(37.3-71.4)$ \\
II & $60.2(59.6-60.9)$ & $62.0(60.4-63.5)$ & $59.2(51.2-66.3)$ \\
III & $45.3(44.5-46.0)$ & $42.8(41.0-44.7)$ & $28.0(23.2-32.9)$ \\
IV & $8.1(7.5-8.7)$ & $7.6(6.3-9.1)$ & $2.8(1.1-6.1)$ \\
All stages & $51.6(51.3-52.0)$ & $48.8(47.8-49.8)$ & $30.1(26.7-33.5)$ \\
\hline
\end{tabular}

AC, adenocarcinoma; MC, mucinous adenocarcinoma; SRCC, signet-ring cell carcinoma. 

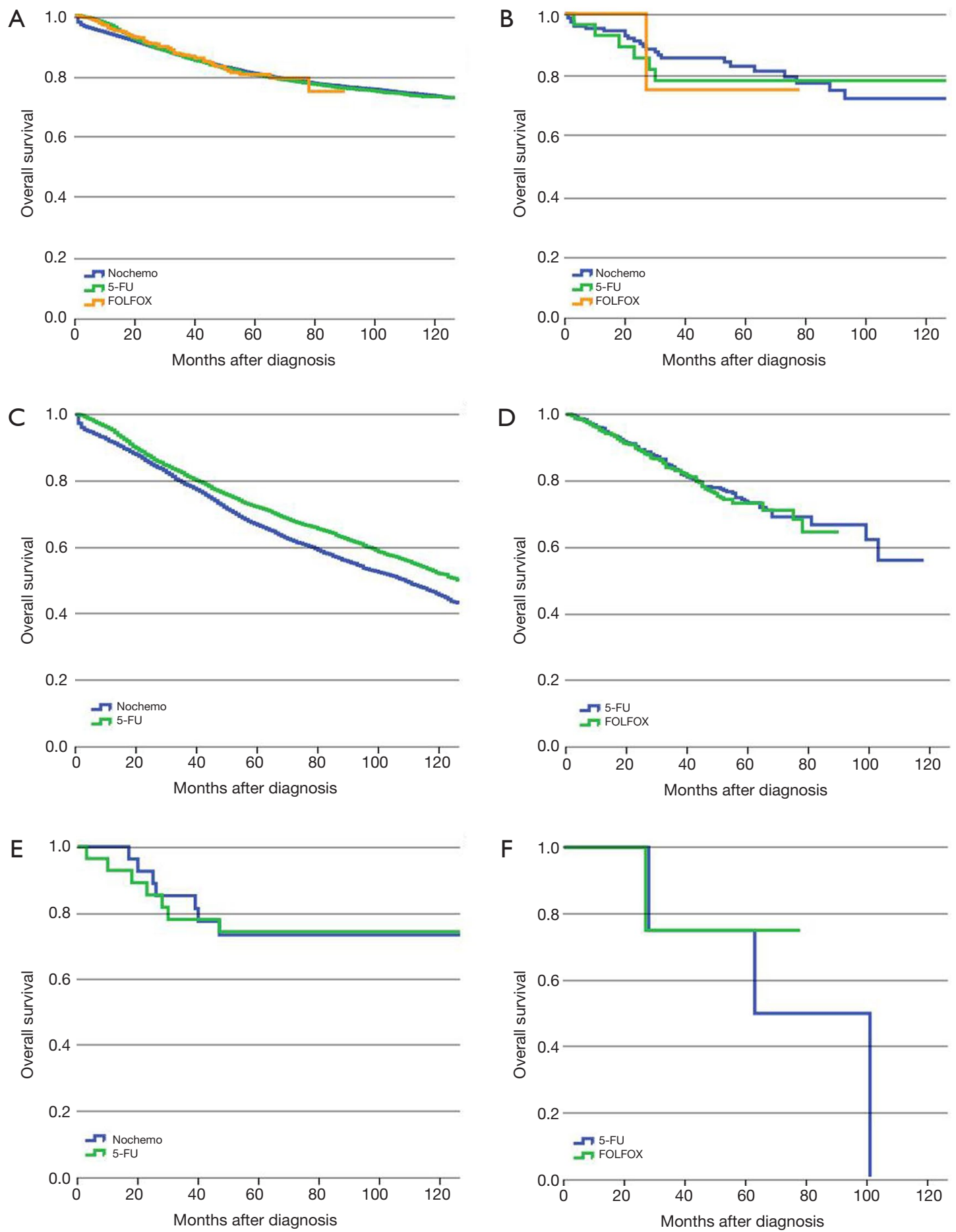

Figure 2 OS in stage II colon cancer patients with AC and SRCC. (A) OS in stage II AC patients who received surgery; (B) OS in stage II SRCC patients who received surgery; (C) after PS-match, the OS in stage II AC patients who received 5-FU regimen or not after surgery; (D) after PS-match, the OS in stage II AC patients who received 5-FU or FOLFOX regimens after surgery; (E) after PS-match, the OS in stage II SRCC patients who received 5-FU regimen or not after surgery; (F) after PS-match, the OS in stage II SRCC patients who received 5-FU or FOLFOX regimens after surgery. OS, overall survival; AC, adenocarcinoma; MC, mucinous adenocarcinoma; SRCC, signet-ring cell carcinoma; PS, propensity score. 
Table 3 Multivariable analysis of factors associated with OS in stage II colon cancer patients

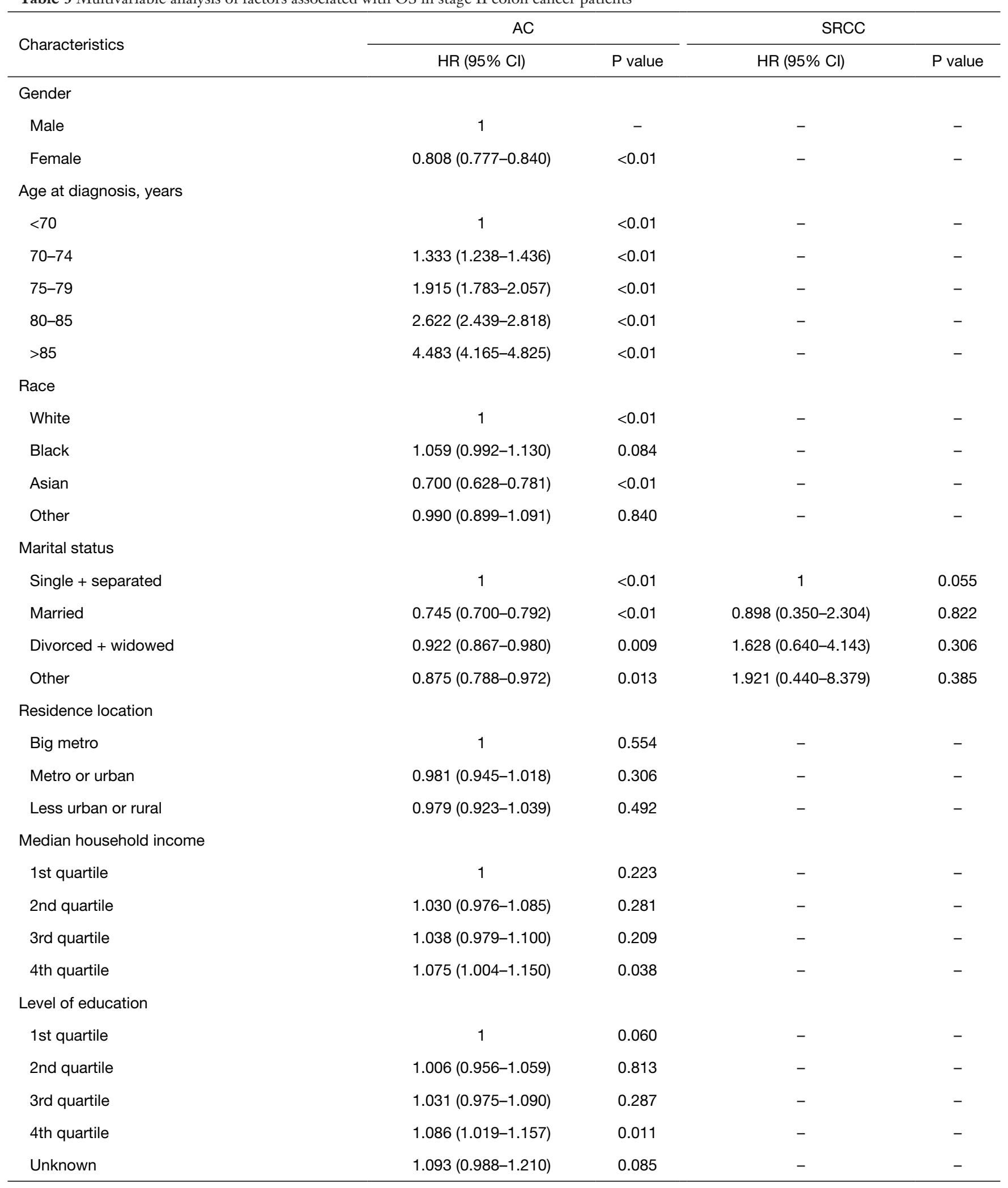

Table 3 (continued) 
Table 3 (continued)

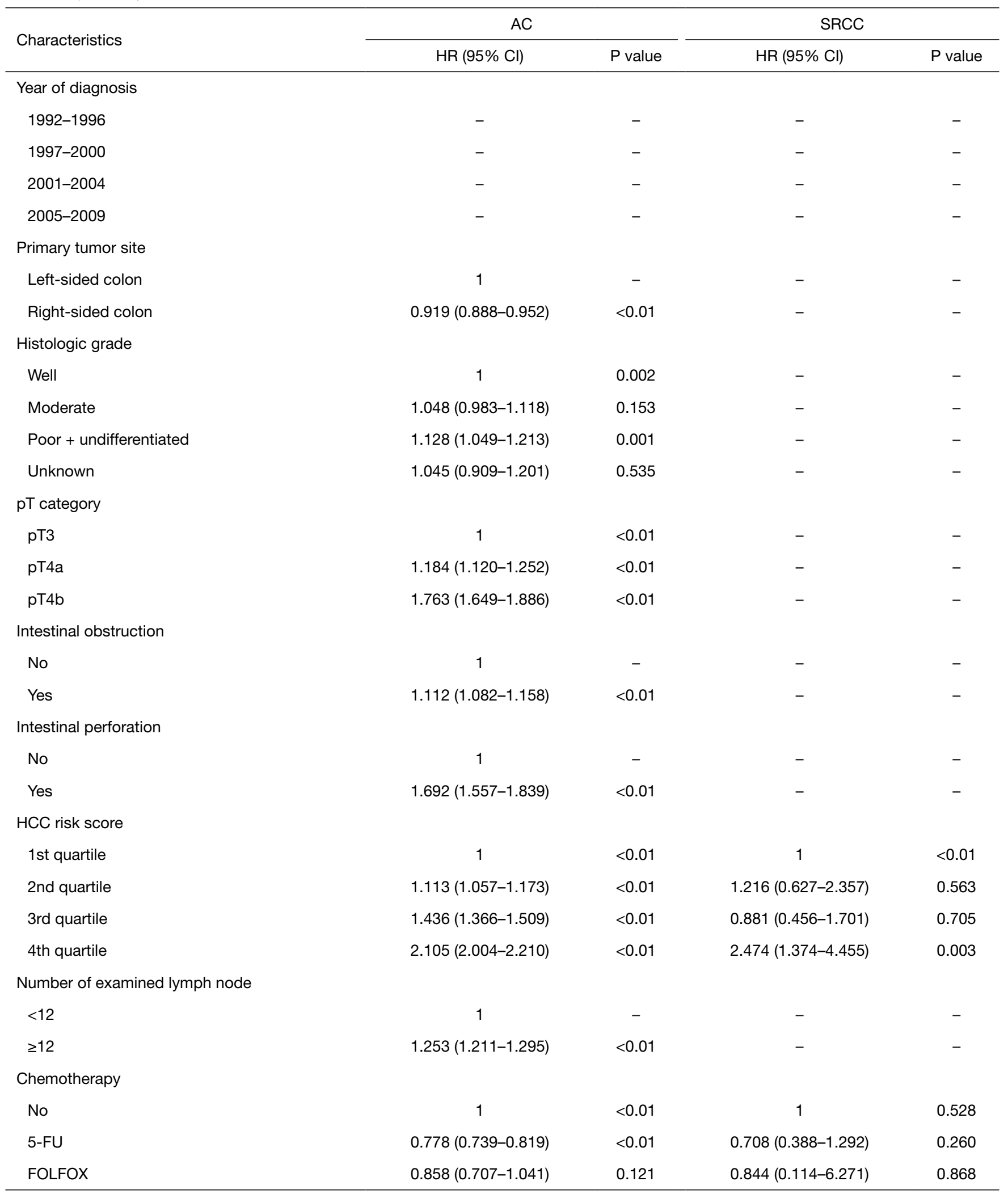

OS, overall survival; AC, adenocarcinoma; SRCC, signet-ring cell carcinoma. 
received adjuvant chemotherapy compared with $54.5 \%$ of AC patients. The prognosis for patients with stage III AC in the no-chemo group was significantly worse than those in the 5 -FU group $(\mathrm{P}<0.01)$. Similar results were found in SRCC patients $(\mathrm{P}<0.01)$. Furthermore, patients with AC who received a FOLFOX regimen had a significantly improved prognosis compared with the 5-FU group $(\mathrm{P}<0.01)$ (Figure $3 A)$. However, we did not observe a similar survival benefit for patients with stage III SRCC receiving a FOLFOX regimen compared with a $5-\mathrm{FU}$ regimen $(\mathrm{P}=0.063)$ (Figure $3 B)$. The 5 -year survival rates of SRCC patients were $18.2 \%$ (95\% CI, $12.5-24.7 \%$ ), $33.3 \%$ (95\% CI, $25.8-41.0 \%$ ) and $51.9 \%$ (95\% CI, 34.0-67.2\%) in nochemo, 5-FU and FOLFOX groups, respectively. The independent prognostic factors for OS were analyzed by using a Cox proportional hazards model (Table 4).

Similarly, we also used the PS-matched cohorts to recalculate the above mentioned results. For patients with AC, the relevant confounding factors after PS-matched analysis of 5-FU group and no-chemo group included age, race, marital status, income, level of education, year of diagnosis, primary tumor site, histologic grade, pT category, $\mathrm{pN}$ category, intestinal obstruction, intestinal perforation, HCC risk score and number of examined lymph node. The relevant confounding factors of 5-FU group and FOLFOX group included gender, age, race, marital status, level of education, year of diagnosis, primary tumor site, histologic grade, pT category, pN category, intestinal obstruction, intestinal perforation and HCC risk score. For patients with stage III SRCC, the relevant confounding factors after PS-matched analysis of 5-FU group and no-chemo group included histologic grade, pT category and $\mathrm{pN}$ category, while age, race, $\mathrm{pT}$ category, $\mathrm{pN}$ category and intestinal obstruction were included in analysis of 5-FU group and FOLFOX group. Using PS-matched cohorts, the prognosis of stage III AC patients in the nochemo group was significantly poorer than the 5-FU group $(\mathrm{P}<0.01)$ (Figure 3C). AC patients who received a FOLFOX regimen had a better prognosis than patients in the $5-\mathrm{FU}$ group $(\mathrm{P}<0.01)$ (Figure $3 D)$. After revising the data with PSmatched cohorts, we found that there was still a significantly different prognosis between stage III SRCC patients in the no-chemo group and the 5 -FU group $(\mathrm{P}<0.01)$ (Figure $3 E$ ). Furthermore, PS-matched cohorts showed a statistically significant improvement in survival of SRCC patients in the FOLFOX group compared to 5 -FU group $(\mathrm{P}=0.036)$ (Figure 3F).

\section{Treatment for stage IV SRCC colon cancer patients}

For stage IV patients, $42.1 \%$ of SRCC patients received perioperative treatment, compared to $46.8 \%$ of AC patients. The prognosis of all histological subtypes of colon cancer patients without any treatment was significantly worse than patients in other groups. For patients with AC, FOLFOX/ FOLFIRI regimens could provide more of a benefit for OS than a $5-\mathrm{FU}$ regimen $(\mathrm{P}<0.01)$. When considering FOLFOX/FOLIRI regimens, adding Bevacizumab improved the prognosis of AC patients compared to a 5 -FU regimen $(\mathrm{P}<0.01)$, but did not improve the effect of FOLFOX/FOLIRI regimens $(\mathrm{P}=0.209)$ (Figure $4 A)$. However, the prognostic impact of distinct regimens on the AC subtype was not completely identical to the SRCC subtype. Considering stage IV SRCC patients, there was no significant difference between the 5 -FU group and FOLFOX/FOLIRI group $(\mathrm{P}=0.954), 5$-FU group and Bevacizumab group $(\mathrm{P}=0.235)$, or FOLFOX/FOLIRI group and Bevacizumab group $(\mathrm{P}=0.187)$ (Figure $4 B)$. A Cox proportional hazards model was also presented to verify the independent prognostic factors (Table 5).

\section{Discussion}

SRCC is an uncommon histological subtype of CRC, which has been reported to have a poor prognosis compared to other subtypes of CRC, such as AC and MC. In our present population-based investigation, we found that the prognosis of SRCC patients who received surgery is much worse than AC and MC patients, especially in stage III and IV patients. We also evaluated the effect of different regimens of adjuvant chemotherapy on stage II and III patients, and the effect of perioperative treatment on stage IV colon SRCC patients. The results indicated that colon SRCC patients seemed to benefit from adjuvant chemotherapy and perioperative treatment.

Currently, the main treatment for advanced colon cancer is surgery plus chemotherapy. For stage II colon cancer patients, O'Connor et al. analyzed whether adjuvant chemotherapy could improve OS by analyzing data from the SEER-Medicare database spanning 1992 to 2005 (16). They found that adjuvant chemotherapy did not provide a benefit for stage II colon cancer patients. Our present study demonstrated that stage II AC patients could benefit from 5-FU based adjuvant chemotherapy following resection, but there may not be a significant effect for stage II SRCC 

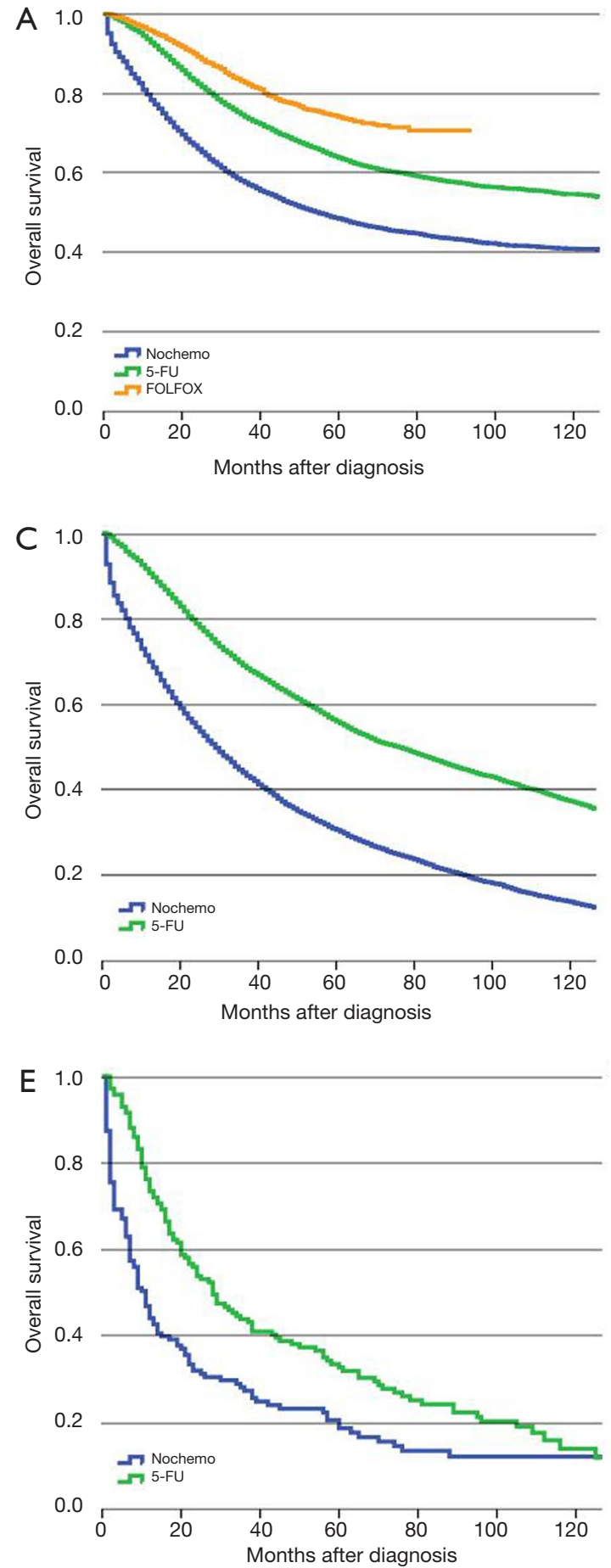
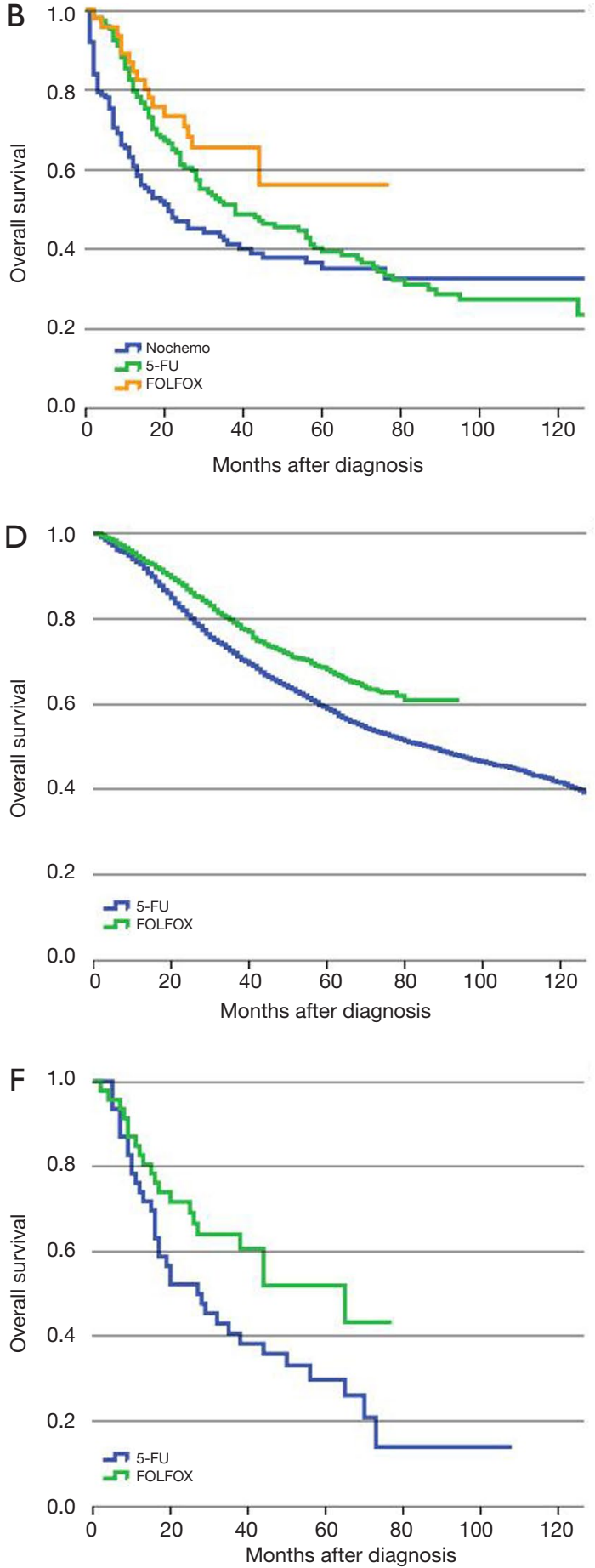

Figure 3 OS in stage III colon cancer patients with AC and SRCC. (A) OS in stage III AC patients who received surgery; (B) OS in stage III SRCC patients who received surgery; (C) after PS-match, the OS in stage III AC patients who received 5-FU regimen or not after surgery; (D) after PS-match, the OS in stage III AC patients who received 5-FU or FOLFOX regimens after surgery; (E) after PS-match, the OS in stage III SRCC patients who received 5-FU regimen or not after surgery; (F) after PS-match, the OS in stage III SRCC patients who received 5-FU or FOLFOX regimens after surgery. OS, overall survival; AC, adenocarcinoma; MC, mucinous adenocarcinoma; SRCC, signet-ring cell carcinoma. 
Table 4 Multivariable analysis of factors associated with OS in stage III colon cancer patients

\begin{tabular}{|c|c|c|c|c|}
\hline Characteristics & \multicolumn{2}{|l|}{$A C$} & \multicolumn{2}{|l|}{ SRCC } \\
\hline \multicolumn{5}{|l|}{ Gender } \\
\hline Female & - & - & - & - \\
\hline \multicolumn{5}{|l|}{ Age at diagnosis, years } \\
\hline $70-74$ & $1.194(1.115-1.278)$ & $<0.01$ & $0.973(0.624-1.518)$ & 0.904 \\
\hline $75-79$ & $1.451(1.357-1.550)$ & $<0.01$ & $1.391(0.892-2.169)$ & 0.146 \\
\hline $80-85$ & 1.650 (1.539-1.769) & $<0.01$ & $1.729(1.106-2.704)$ & 0.016 \\
\hline$>85$ & $2.197(2.041-2.365)$ & $<0.01$ & $1.600(0.985-2.601)$ & 0.058 \\
\hline Asian & $0.664(0.596-0.741)$ & $<0.01$ & - & - \\
\hline Other & $0.925(0.843-1.014)$ & 0.095 & - & - \\
\hline \multicolumn{5}{|l|}{ Marital status } \\
\hline Single + separated & 1 & $<0.01$ & - & - \\
\hline Married & $0.868(0.813-0.927)$ & $<0.01$ & - & - \\
\hline Divorced + widowed & $0.942(0.882-1.006)$ & 0.076 & - & - \\
\hline Other & $0.890(0.791-1.002)$ & 0.053 & - & - \\
\hline \multicolumn{5}{|l|}{ Residence location } \\
\hline 2nd quartile & $0.973(0.920-1.030)$ & 0.342 & - & - \\
\hline 3rd quartile & $0.941(0.884-1.002)$ & 0.057 & - & - \\
\hline 4th quartile & $0.938(0.872-1.008)$ & 0.081 & - & - \\
\hline \multicolumn{5}{|l|}{ Level of education } \\
\hline 1st quartile & 1 & $<0.01$ & - & - \\
\hline 2nd quartile & $1.089(1.031-1.151)$ & 0.002 & - & - \\
\hline 3rd quartile & $1.095(1.030-1.164)$ & 0.004 & - & - \\
\hline 4th quartile & $1.181(1.102-1.265)$ & $<0.01$ & - & - \\
\hline Unknown & 1.203 (1.079-1.341) & 0.001 & - & - \\
\hline \multicolumn{5}{|l|}{ Year of diagnosis } \\
\hline 1992-1996 & 1 & $<0.01$ & 1 & 0.062 \\
\hline $1997-2000$ & $0.988(0.936-1.041)$ & 0.643 & $1.134(0.772-1.665)$ & 0.521 \\
\hline 2001-2004 & $0.948(0.900-0.998)$ & 0.040 & $1.017(0.704-1.468)$ & 0.930 \\
\hline
\end{tabular}

Table 4 (continued) 
Table 4 (continued)

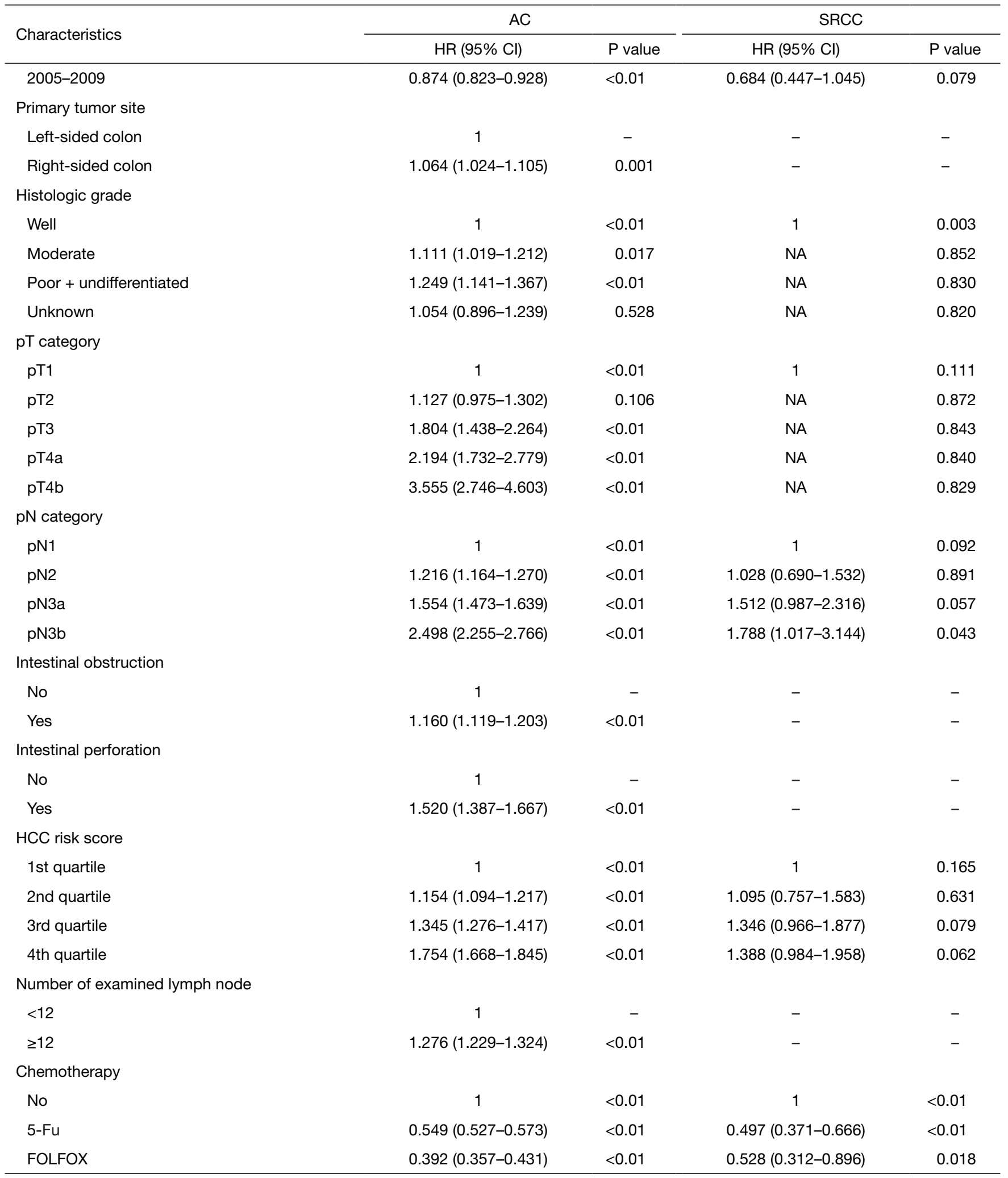

OS, overall survival; AC, adenocarcinoma; SRCC, signet-ring cell carcinoma. 

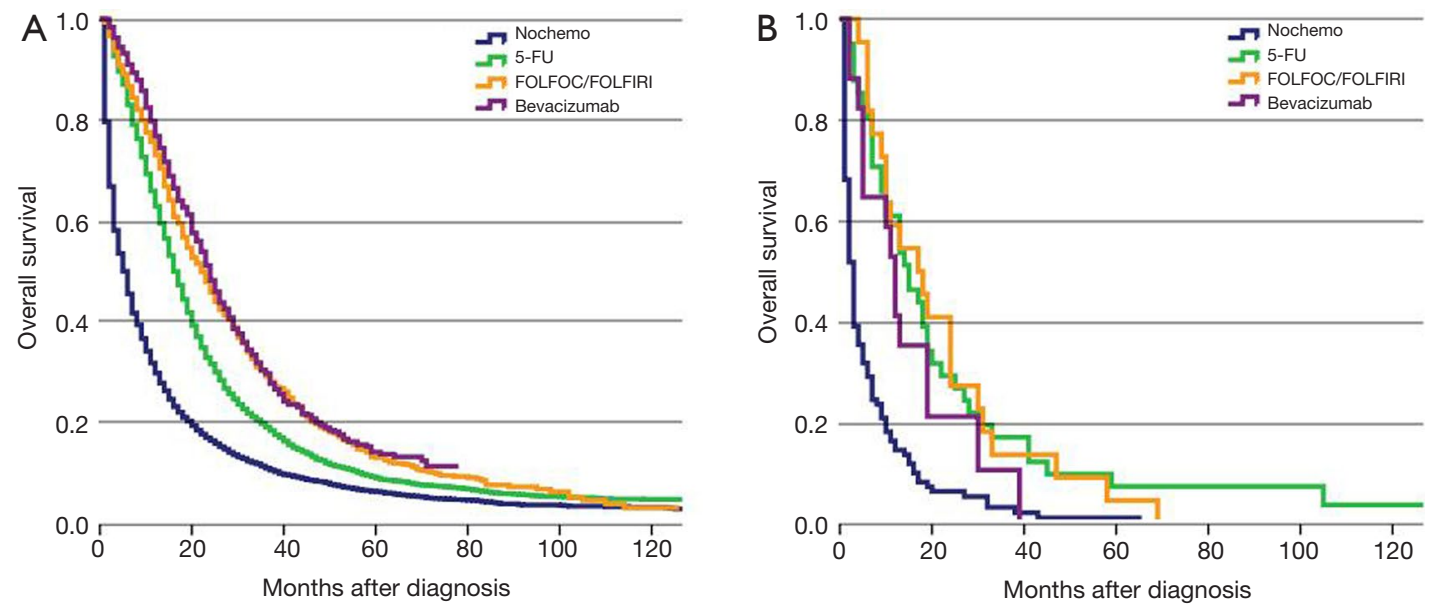

Figure 4 OS in stage IV colon cancer patients with AC and SRCC. (A) OS in stage IV AC patients who received different adjuvant therapy regimens after surgery; (B) OS in stage IV SRCC patients who received different adjuvant therapy regimens after surgery. OS, overall survival; AC, adenocarcinoma; MC, mucinous adenocarcinoma; SRCC, signet-ring cell carcinoma.

Table 5 Multivariable analysis of factors associated with OS in stage IV colon cancer patients

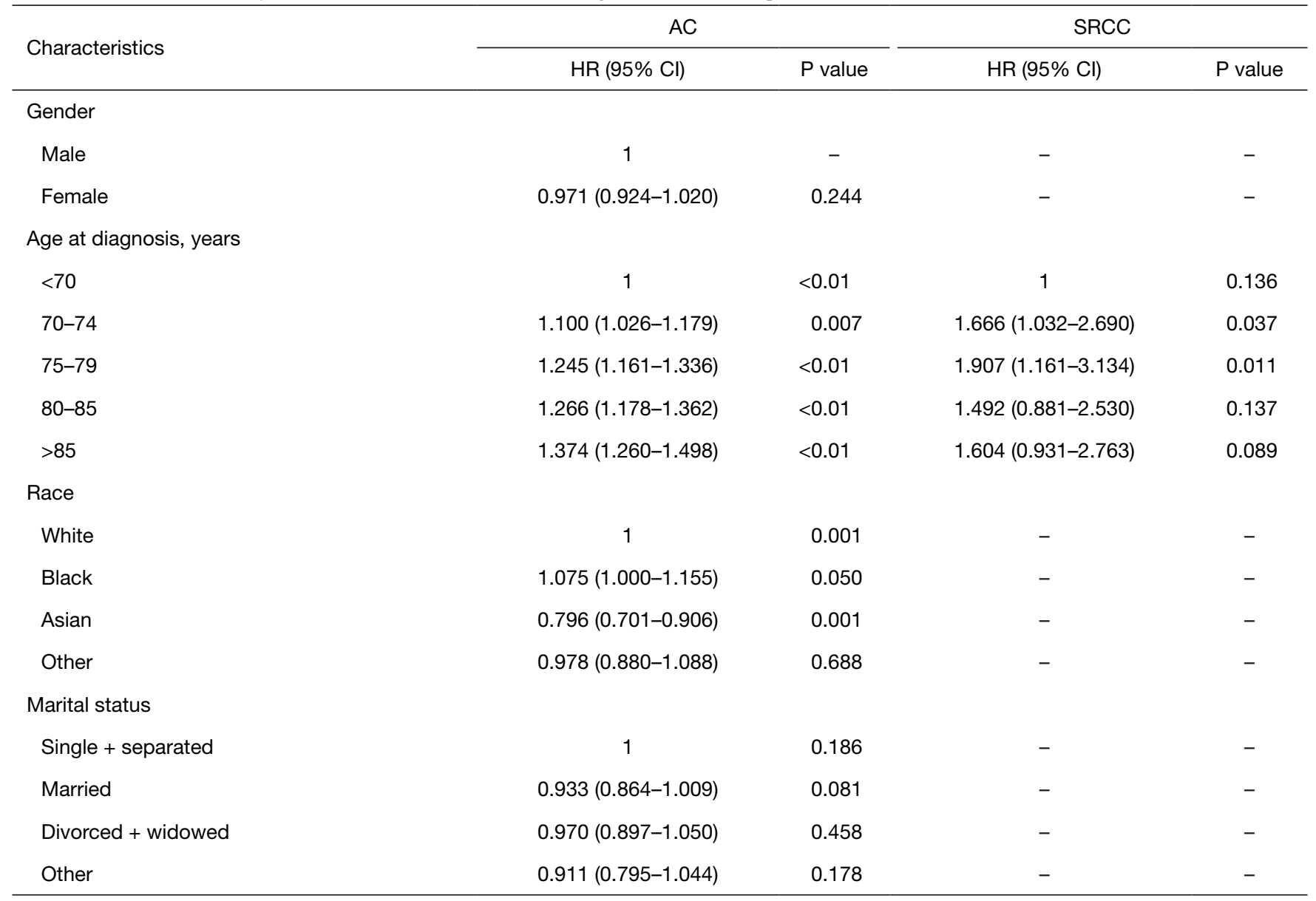

Table 5 (continued) 
Table 5 (continued)

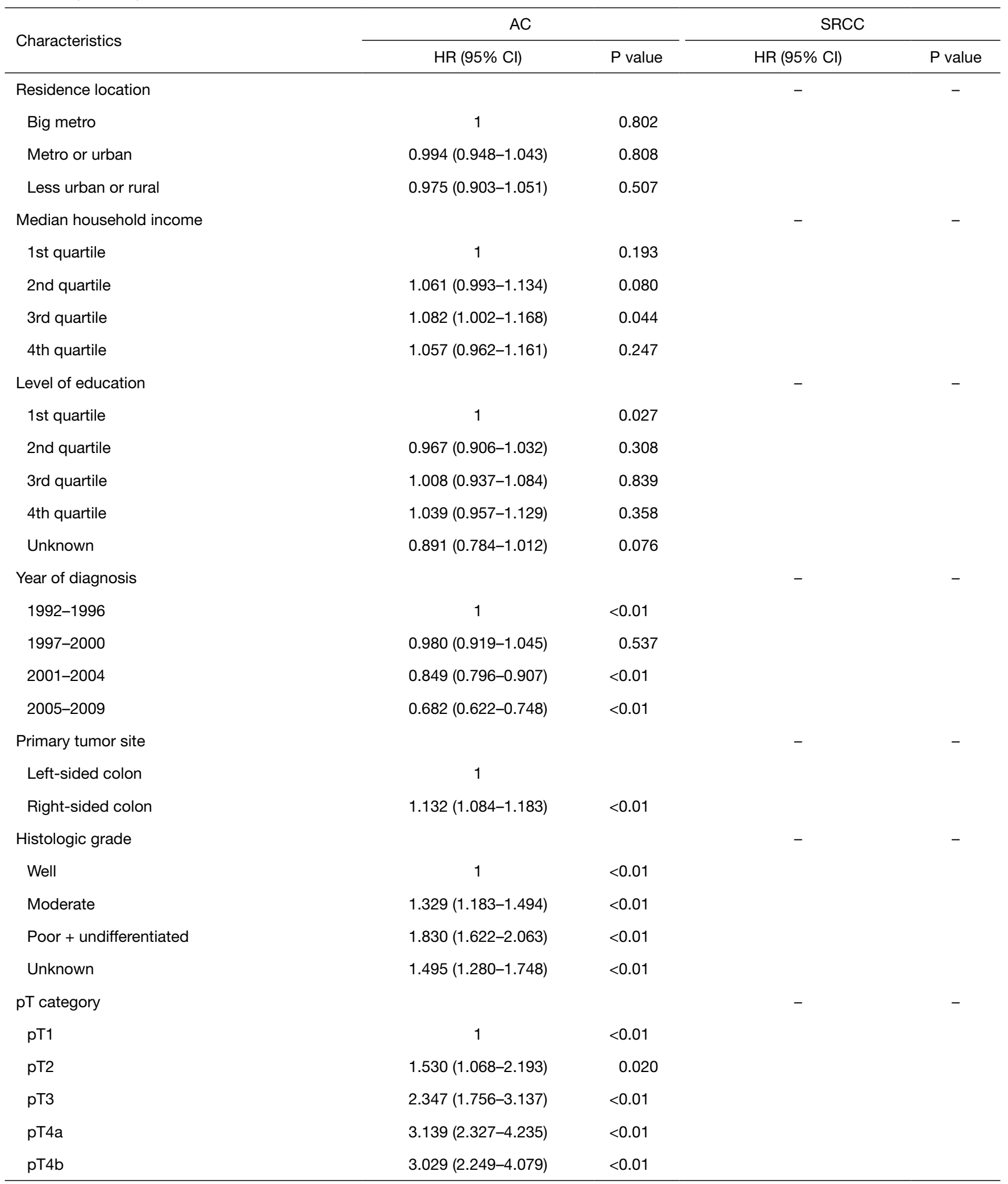

Table 5 (continued) 
Table 5 (continued)

\begin{tabular}{|c|c|c|c|c|}
\hline Characteristics & \multicolumn{2}{|l|}{$A C$} & \multicolumn{2}{|l|}{ SRCC } \\
\hline Unknown & $2.479(1.853-3.317)$ & $<0.01$ & & \\
\hline \multicolumn{5}{|l|}{ pN category } \\
\hline pNO & 1 & $<0.01$ & 1 & 0.022 \\
\hline $\mathrm{pN} 2$ & $1.264(1.187-1.346)$ & $<0.01$ & $0.591(0.314-1.113)$ & 0.104 \\
\hline $\mathrm{pN} 3 \mathrm{a}$ & $1.490(1.400-1.586)$ & $<0.01$ & $1.254(0.701-2.241)$ & 0.446 \\
\hline $\mathrm{pN} 3 \mathrm{~b}$ & $1.980(1.857-2.110)$ & $<0.01$ & $1.471(0.977-2.213)$ & 0.064 \\
\hline \multicolumn{5}{|l|}{ Intestinal obstruction } \\
\hline \multicolumn{5}{|l|}{ Intestinal perforation } \\
\hline No & - & - & - & - \\
\hline Yes & - & - & - & - \\
\hline \multicolumn{5}{|l|}{ HCC risk score } \\
\hline 1st quartile & 1 & $<0.01$ & - & - \\
\hline 2nd quartile & $1.014(0.947-1.086)$ & 0.685 & - & - \\
\hline 3rd quartile & 1.082 (1.014-1.154) & 0.017 & - & - \\
\hline 4th quartile & $1.185(1.110-1.265)$ & $<0.01$ & - & - \\
\hline \multicolumn{5}{|l|}{ Chemotherapy } \\
\hline No & 1 & $<0.01$ & 1 & $<0.01$ \\
\hline $5-\mathrm{FU}$ & $0.523(0.497-0.551)$ & $<0.01$ & $0.344(0.228-0.519)$ & $<0.01$ \\
\hline FOLFOX or FOLFIRI & $0.478(0.442-0.516)$ & $<0.01$ & $0.358(0.216-0.593)$ & $<0.01$ \\
\hline Chemo + BEV & $0.457(0.416-0.503)$ & $<0.01$ & $0.456(0.255-0.814)$ & 0.008 \\
\hline
\end{tabular}

OS, overall survival; AC, adenocarcinoma; SRCC, signet-ring cell carcinoma.

patients. Why was it different from results of stage II AC patients in SRCC group? Firstly, the sample size might be a key factor influencing the whole results. There were 22,539 patients in stage II AC group and only 180 patients in SRCC group, the small sample size of SRCC group may help explain the statistically negative results. Secondly, the molecular characteristics of colonic SRCC may be another reason causing the difference. Bellan A reported that the expression of P53 protein was down regulated in colonic SRCC cells, which means this kind of cancer cells might show resistance to chemotherapy $(27,28)$. What's more, Pozos-Ochoa et al. found CK20, MUC5AC had a higher proportion of negativity in colonic SRCC cells which may cause resistance to anti-tumor drugs like 5-FU (29-31). To further investigate this issue, more researches of larger sample size and more comprehensive molecular status of 
colonic SRCC patients should be done in the future.

In the 1990s, 5-FU based adjuvant chemotherapy had become the standard regimen for stage III colon cancer patients (32). In 2004, the MOSAIC trial reported that the addition of oxaliplatin to 5 -FU based adjuvant chemotherapy could improve OS and disease-free survival of patients with stage III colon cancer. This finding made the FOLFOX regimen the new standard for stage III patients following resection (33). While oxaliplatin was found to increase the survival rate of CRC patients, side effects such as cytopenias, diarrhea, vomiting and peripheral neuropathy were more likely to occur with a FOLFOX regimen than with a $5-\mathrm{FU}$ regimen (34). To avoid side effects brought on by adjuvant chemotherapy, regimens should be selected according to their effectiveness against specific malignancies. Therefore, we analyzed the OS of stage III colon cancer patients with different histologic subtypes to determine the effect of adjuvant chemotherapy on individual CRC subtypes. The results suggest that stage III CRC patients benefit from 5-FU based adjuvant chemotherapy after surgery and that the addition of oxaliplatin could enhance the effect of this treatment for both AC and SRCC patients. Therefore, patients with stage III colon cancer should receive standard adjuvant chemotherapy without considering histologic subtypes after surgery.

Traditionally, patients with stage IV colon cancer have received palliative systemic therapy attempting to increase OS, and palliative resections to prevent complications such as bleeding and obstruction $(35,36)$. Recently, research from the Netherlands has suggested that patients with stage IV CRC who have received a primary tumor resection may have an improved OS compared to patients who receive systemic therapy without resection of the primary tumor (37). Hence, we performed an analysis to determine whether the histologic subtype could influence the effectiveness of systemic therapy for stage IV colon cancer patients who received surgery. The results indicated a significant survival benefit for AC patients who received surgery plus systemic therapy with 5-FU compared with AC patients who only received surgery. Furthermore, addition of oxaliplatin or irinotecan to 5-FU regimen could improve AC patients' OS compared to patients who received 5-FU only. Addition of bevacizumab did not show an enhanced benefit compared to FOLFOX/FOLFIRI regimens, which might be due to the small sample size who had received bevacizumab. Moreover, the prognosis of stage IV SRCC patients who received surgery without systemic therapy was worse than that of patients who received surgery plus systemic therapy. However, we did not observe any significant benefit among different regimens of perioperative systemic therapy for SRCC patients. From the above results, we found that patients with stage IV colon cancer should be treated with both surgery and systemic therapy if patients can tolerate the therapeutic regimens. Additionally, the histological subtypes should be considered as a factor for the prognosis and selection of therapy. Nevertheless, the above findings had some difference from the advantage of clinical trial regarding adding Bevacizumab to FOLFOX/FOLIRI. First of all, we thought that the selection of patients could be a potential concern in our present study. We extracted data of stage IV colon SRCC patients who received surgery and following systemic therapy within 9 months after resection in our work. However, in other clinical trials, some of them chose patients with metastasis but did not receive surgery or stage IV patients received resection but with different histological classifications mixed together $(38,39)$. Thus, different patient selection among different studies might explain the different results exhibited in our present study and some clinical trials. Besides, in the Bevacizumab group, we included all patients who received Bevacizumab agent with 5-FU-based chemotherapy including 5-FU and FOLFOX/FOLFIRI regimens due to the small sample sizes. Still, many researches focusing on the efficiency of Bevacizumab for stage IV colon cancer got negative results, which may owe to the failure to comprehensively consider some important factors like the sideness of colon cancer as some studies recommended that bevacizumab treatment should preferentially go to patients with primary right-sided or left-sided colon cancer patients $(40,41)$. The NCCN guidelines indicates that no data directly address whether bevacizumab should be used with chemotherapy in the perioperative treatment of resectable metastatic disease and does not recommend the use of bevacizumab for the perioperative stage IV colon cancer. We believe that more large and well-designed researches would be done and get a more solid conclusion for this issue in the future.

Our present study has some potential limitations. First, this study was a retrospective analysis, and there might be some inevitable inaccuracies in the SEER-Medicare database as it is a population-based registration database. Second, the number of patients age $<65$ years at the time of diagnosis was absent from our study, which influenced some results such as the relationship between the occurrence of SRCC and the ages of patients. Third, we were not able to 
analyze the benefit of adjuvant chemotherapy in low-risk stage II patients, due to the low number of patients who received chemotherapy in this group. Fourth, the sample sizes, especially in SRCC groups of each stage, were not large enough for us to analyze subgroups as detailed as possible. As we tried to find whether patients with colon SRCC cancer could get benefit from adjuvant systemic therapy after surgery, there may be a selection bias hidden in the results which might cause difference between the results from our research and other clinical trials. Due to the existence of these limitations, the results of this study should be considered prudently.

\section{Conclusions}

In conclusion, we found that the prognosis of patients with colon SRCC was significantly worse than other histological subtypes. The effective role of adjuvant chemotherapy or systemic therapy for survival was shown mainly in stage III and IV SRCC patients who received surgery. In the future, histological subtypes should be individually considered during the process of therapeutic selection. However, results from randomized controlled trials are still needed to characterize the relationship between CRC subtypes and therapeutic effectiveness.

\section{Acknowledgments}

Funding: This work was supported by Clinical Capability Construction Project for Liaoning Provincial Hospitals (LNCCC-A01-2014), the Key Laboratory Programme of Education Department of Liaoning Province (LZ2015076) and National Key R \& D Program of China (MOST2017YFC0908300, MOST-2017YFC0908305).

\section{Footnote}

Conflicts of Interest: All authors have completed the ICMJE uniform disclosure form (available at http://dx.doi. org/10.21037/tcr.2018.07.14). The authors have no conflicts of interest to declare.

Ethical Statement: The authors are accountable for all aspects of the work in ensuring that questions related to the accuracy or integrity of any part of the work are appropriately investigated and resolved. The study was conducted in accordance with the Declaration of Helsinki (as revised in 2013). The permission to access the research data file in SEER-Medicare program was obtained by the authors (reference no. D6-MEDIC-821). The study was approved by the Institutional Review Board of the First Hospital of China Medical University \{reference no. [2012] 96\}. Because the SEER-Medicare data are de-identified and are based on registry data, no prior informed consent was required.

Open Access Statement: This is an Open Access article distributed in accordance with the Creative Commons Attribution-NonCommercial-NoDerivs 4.0 International License (CC BY-NC-ND 4.0), which permits the noncommercial replication and distribution of the article with the strict proviso that no changes or edits are made and the original work is properly cited (including links to both the formal publication through the relevant DOI and the license). See: https://creativecommons.org/licenses/by-nc-nd/4.0/.

\section{References}

1. Siegel RL, Miller KD, Fedewa SA, et al. Colorectal cancer statistics, 2017. CA Cancer J Clin 2017;67:177-93.

2. Torre LA, Bray F, Siegel RL, et al. Global cancer statistics, 2012. CA Cancer J Clin 2015;65:87-108.

3. Bosman FT, Carneiro F, Hruban RH, et al. WHO Classification of Tumours of the Digestive System, Fourth Edition. IARC WHO Classification of Tumours. WHO Press, 2010.

4. Du W, Mah JT, Lee J, et al. Incidence and survival of mucinous adenocarcinoma of the colorectum: a population-based study from an Asian country. Dis Colon Rectum 2004;47:78-85.

5. Hyngstrom JR, Hu CY, Xing Y, et al. Clinicopathology and outcomes for mucinous and signet ring colorectal adenocarcinoma: analysis from the National Cancer Data Base. Ann Surg Oncol 2012;19:2814-21.

6. Laufman H, Saphir O. Primary linitis plastica type of carcinoma of the colon. AMA Arch Surg 1951;62:79-91.

7. Nitsche U, Zimmermann A, Spath C, et al. Mucinous and signet-ring cell colorectal cancers differ from classical adenocarcinomas in tumor biology and prognosis. Ann Surg 2013;258:775-82; discussion 82-3.

8. Thota R, Fang X, Subbiah S. Clinicopathological features and survival outcomes of primary signet ring cell and mucinous adenocarcinoma of colon: retrospective analysis of VACCR database. J Gastrointest Oncol 2014;5:18-24.

9. Sung CO, Seo JW, Kim KM, et al. Clinical significance of signet-ring cells in colorectal mucinous adenocarcinoma. 
Mod Pathol 2008;21:1533-41.

10. Borger ME, Gosens MJ, Jeuken JW, et al. Signet ring cell differentiation in mucinous colorectal carcinoma. J Pathol 2007;212:278-86.

11. Wei Q, Wang X, Gao J, et al. Clinicopathologic and Molecular Features of Colorectal Adenocarcinoma with Signet-Ring Cell Component. PLoS One 2016;11:e0156659.

12. Lee HS, Soh JS, Lee S, et al. Clinical Features and Prognosis of Resectable Primary Colorectal Signet-Ring Cell Carcinoma. Intest Res 2015;13:332-8.

13. Inamura K, Yamauchi M, Nishihara R, et al. Prognostic significance and molecular features of signet-ring cell and mucinous components in colorectal carcinoma. Ann Surg Oncol 2015;22:1226-35.

14. Hugen N, Verhoeven RH, Lemmens VE, et al. Colorectal signet-ring cell carcinoma: benefit from adjuvant chemotherapy but a poor prognostic factor. Int J Cancer 2015;136:333-9.

15. Benson AB 3rd, Schrag D, Somerfield MR, et al. American Society of Clinical Oncology recommendations on adjuvant chemotherapy for stage II colon cancer. J Clin Oncol 2004;22:3408-19.

16. O'Connor ES, Greenblatt DY, LoConte NK, et al. Adjuvant chemotherapy for stage II colon cancer with poor prognostic features. J Clin Oncol 2011;29:3381-8.

17. Gill S, Loprinzi CL, Sargent DJ, et al. Pooled analysis of fluorouracil-based adjuvant therapy for stage II and III colon cancer: who benefits and by how much? J Clin Oncol 2004;22:1797-806.

18. McCleary NJ, Meyerhardt JA, Green E, et al. Impact of age on the efficacy of newer adjuvant therapies in patients with stage II/III colon cancer: findings from the ACCENT database. J Clin Oncol 2013;31:2600-6.

19. Huang XZ, Gao P, Song YX, et al. Impact of age on efficacy of postoperative oxaliplatin-based chemotherapy in patients with rectal cancer after neoadjuvant chemoradiotherapy. Oncotarget 2016;7:19643-53.

20. Hershman DL, Wright JD, Lim E, et al. Contraindicated use of bevacizumab and toxicity in elderly patients with cancer. J Clin Oncol 2013;31:3592-9.

21. Potosky AL, Riley GF, Lubitz JD, et al. Potential for cancer related health services research using a linked Medicare-tumor registry database. Med Care 1993;31:732-48.

22. Chavez-MacGregor M, Zhang N, Buchholz TA, et al. Trastuzumab-related cardiotoxicity among older patients with breast cancer. J Clin Oncol 2013;31:4222-8.
23. Ash AS, Ellis RP, Pope GC, et al. Using diagnoses to describe populations and predict costs. Health Care Financ Rev 2000;21:7-28.

24. Sobin LH, Gospodarowicz MK, Wittekind C. UICC: TNM classification of malignant tumours, 7th ed. Oxford: Wiley-Blackwell; 2009.

25. Rubin DB. Estimating causal effects from large data sets using propensity scores. Ann Intern Med 1997;127:757-63.

26. Leuven E, Sianesi B. PSMATCH2: Stata module to perform full Mahalanobis and propensity score matching, common support graphing, and covariate imbalance testing. Statistical Software Components 2015.

27. Bellan A, Cappellesso R, Lo Mele M, et al. Early signet ring cell carcinoma arising from colonic adenoma: the molecular profiling supports the adenoma-carcinoma sequence. Hum Pathol 2016;50:183-6.

28. Cannell IG, Merrick KA, Morandell S, et al. A Pleiotropic RNA-Binding Protein Controls Distinct Cell Cycle Checkpoints to Drive Resistance of p53-Defective Tumors to Chemotherapy. Cancer Cell 2015;28:623-37.

29. Pozos-Ochoa LI, Lino-Silva LS, Leon-Takahashi AM, et al. Prognosis of Signet Ring Cell Carcinoma of the Colon and Rectum and their Distinction of Mucinous Adenocarcinoma with Signet Ring Cells. A Comparative Study. Pathol Oncol Res 2018;24:609-16.

30. Hinz S, Roder C, Tepel J, et al. Cytokeratin 20 positive circulating tumor cells are a marker for response after neoadjuvant chemoradiation but not for prognosis in patients with rectal cancer. BMC Cancer 2015;15:953.

31. Leteurtre E, Gouyer V, Rousseau K, et al. Differential mucin expression in colon carcinoma HT-29 clones with variable resistance to 5-fluorouracil and methotrexate. Biol Cell 2004;96:145-51.

32. Schistosomes, liver flukes and Helicobacter pylori. IARC Working Group on the Evaluation of Carcinogenic Risks to Humans. Lyon, 7-14 June 1994. IARC Monogr Eval Carcinog Risks Hum 1994;61:1-241.

33. Suerbaum S, Michetti P. Helicobacter pylori infection. N Engl J Med 2002;347:1175-86.

34. Demetriou CA, Straif K, Vineis P. From testing to estimation: the problem of false positives in the context of carcinogen evaluation in the IARC monographs. Cancer Epidemiol Biomarkers Prev 2012;21:1272-81.

35. Everatt R, Tamosiunas A, Kuzmickiene I, et al. Alcohol consumption and risk of gastric cancer: a cohort study of men in Kaunas, Lithuania, with up to 30 years follow-up. BMC Cancer 2012;12:475.

36. Fox JG, Wang TC. Inflammation, atrophy, and gastric 
cancer. J Clin Invest 2007;117:60-9.

37. Gonzalez CA, Pera G, Agudo A, et al. Smoking and the risk of gastric cancer in the European Prospective Investigation Into Cancer and Nutrition (EPIC). Int J Cancer 2003;107:629-34.

38. Moehler M, Sprinzl MF, Abdelfattah M, et al. Capecitabine and irinotecan with and without bevacizumab for advanced colorectal cancer patients. World J Gastroenterol 2009; 15:449-56.

39. Giessen C, von Weikersthal LF, Hinke A, et al. A randomized, phase III trial of capecitabine plus bevacizumab (Cape-Bev) versus capecitabine plus

Cite this article as: Sun J, Wang X, Gao P, Song Y, Chen X, Sun Y, Yu D, Lv X, Wang Z. Prognosis and efficiency of adjuvant therapy in resected colon signet-ring cell carcinoma. Transl Cancer Res 2018;7(4):1006-1025. doi: 10.21037/ tcr.2018.07.14 irinotecan plus bevacizumab (CAPIRI-Bev) in first-line treatment of metastatic colorectal cancer: the AIO KRK 0110 trial/ML22011 trial. BMC Cancer 2011;11:367.

40. Cremolini C, Antoniotti C, Lonardi S, et al. Primary tumor sidedness and benefit from FOLFOXIRI plus bevacizumab as initial therapy for metastatic colorectal cancer. Retrospective analysis of the TRIBE trial by GONO. Ann Oncol 2018. [Epub ahead of print].

41. Boisen MK, Johansen JS, Dehlendorff C, et al. Primary tumor location and bevacizumab effectiveness in patients with metastatic colorectal cancer. Ann Oncol 2013;24:2554-9. 